\title{
Multimodality Imaging of Breast Parenchymal Density and Correlation with Risk Assessment
}

\author{
Georg J. Wengert ${ }^{1} \cdot$ Thomas H. Helbich ${ }^{1}$ • Doris Leithner ${ }^{2}$ • Elizabeth A. Morris ${ }^{3}$ • Pascal A. T. Baltzer ${ }^{1} \cdot$ Katja Pinker $^{1,3}$
}

Published online: 17 January 2019

(C) The Author(s) 2019

\begin{abstract}
Purpose of Review Breast density, or the amount of fibroglandular tissue in the breast, has become a recognized and independent marker for breast cancer risk. Public awareness of breast density as a possible risk factor for breast cancer has resulted in legislation for risk stratification purposes in many US states. This review will provide a comprehensive overview of the currently available imaging modalities for qualitative and quantitative breast density assessment and the current evidence on breast density and breast cancer risk assessment.

Recent Findings To date, breast density assessment is mainly performed with mammography and to some extent with magnetic resonance imaging. Data indicate that computerized, quantitative techniques in comparison with subjective visual estimations are characterized by higher reproducibility and robustness.

Summary Breast density reduces the sensitivity of mammography due to a masking effect and is also a recognized independent risk factor for breast cancer. Standardized breast density assessment using automated volumetric quantitative methods has the potential to be used for risk prediction and stratification and in determining the best screening plan for each woman.
\end{abstract}

Keywords Breast density $\cdot$ Mammography $\cdot$ Ultrasound $\cdot$ Magnetic resonance imaging $\cdot$ Fibroglandular tissue $\cdot$ Breast cancer

\section{Introduction}

Breast density, or breast composition, indicates the amount of fibroglandular tissue in relation to fatty tissue within the breast. Breast tissue composition exists in high variability among women, and is also subject to change during life, influenced by endogenous (age, parity, body mass index, ethnicity) and exogenous (smoking, alcohol, obesity, sedentary lifestyle, oral contraception, hormone replacement therapy)

This article is part of the Topical Collection on Breast Cancer Imaging and Screening

Katja Pinker

pinkerdk@mskcc.org

1 Department of Biomedical Imaging and Image-guided Therapy, Division of Molecular and Gender Imaging, Medical University of Vienna, Vienna, Austria

2 Department of Diagnostic and Interventional Radiology, University Hospital Frankfurt, Frankfurt, Germany

3 Department of Radiology, Breast Imaging Service, Memorial Sloan Kettering Cancer Center, 300 E 66th St, 7th Floor, New York, NY 10065, USA factors (Table 1) [1-4]. Breast density impacts the risk for breast cancer in different ways. There is a strong body of evidence that the sensitivity of mammography for breast cancer detection decreases with increasing breast density $[5,6]$. This so-called masking effect is due to an overlap with normal breast tissue thus obscuring breast lesions and is most pronounced in extremely dense breast parenchyma $[7,8]$. In addition to causing false-negative findings due to the low efficiency of screening mammography [9], breast density may also lead to increased false-positive and recall rates $[10,11]$.

Although the masking effect of breast cancer in dense breast is important, it must be noted that the association between breast density and risk for breast cancer is not merely a masking bias and cannot be explained by the reduced sensitivity of mammography alone. Several studies have consistently shown that breast density is also an independent and strong risk factor for breast cancer [12-17]. The consistent association between increased density and cancer risk emphasizes its potential for risk prediction and risk stratification, and this might become a valuable tool in determining the best screening plan for each woman.

In the past decade, breast density notification laws have been passed with the intent to inform women about their 
Table 1 Summary of endogenous and exogenous factors influencing breast tissue composition to increased breast density (does not claim completeness)

\begin{tabular}{ll}
\hline Endogenous factors & Exogenous factors \\
\hline Older age/postmenopause & Smoking \\
High parity/nulliparity & Alcohol \\
High body mass index & HRT \\
Circulating estrogens/IGF-1 & Oral contraceptive \\
African-American & Obesity \\
Early age at menarche $(\leq 12 \mathrm{a})$ & Sedentary time \\
Older age at first live birth & Physical inactivity \\
CYP1A2 status & Tamoxifen/vit C, D/folate/NSAID \\
\hline
\end{tabular}

own breast density and possible benefits from supplemental screening methods, such as breast ultrasound. As of April 2018, 35 states in the USA have mandated that patients and her primary care physicians be notified with patients' breast density status and the risk posed by the breast density [18•]. Breast density legislation provides a unique opportunity to strengthen patient-provider relationships by encouraging physicians to engage women in a conversation about the limitations, risks, and benefits of screening, as well as to provide women with greater autonomy.

This review will provide a comprehensive overview of the currently available modalities for qualitative and quantitative breast density assessment and the current evidence on breast density and breast cancer risk assessment.

\section{Breast Density Assessment}

\section{Mammography}

The assessment of breast density is usually performed on the mammogram and is defined as the amount of fibroglandular tissue relative to the fatty tissue. On mammography, the fatty components appear radiolucent, while the fibroglandular components, consisting of epithelial and stromal tissue, appear radiopaque. The mammogram is a $2 \mathrm{D}$ image as a $3 \mathrm{D}$ structure. There are several methods available for assessing the mammographic density, ranging from subjective visual assessment to semi-automated methods and automated methods. Currently, there are no recommendations or criteria for standardized breast density assessment $[19,20]$. The subjective or pattern-based assessment methods include Wolfe's classification [21], Tabar patterns [22], Boyd, and Breast Imaging Reporting and Data System (BI-RADS) of the American College of Radiology (ACR) [6]. Semi-automated methods include Cumulus and Madena. Fully automated area-based mammographic density assessment methods include ImageJ, AutoDensity, LIBRA, STRATUS, MedDensity, iReveal, and
Densitas. Fully automated volumetric-based methods are $\mathrm{BD}_{\mathrm{SXA}}$, Cumulus V, Quantra, and Volpara Density.

The BI-RADS lexicon is the most widely used method clinically by radiologists. The current revised 5 th edition of the BI-RADS atlas defines the four breast density/ composition categories as follows: ACR-MG-a, the breasts are almost entirely fatty; ACR-MG-b, there are scattered areas of fibroglandular density; ACR-MG-c, the breasts are heterogeneously dense, which may obscure small masses; and ACRMG-d, the breasts are extremely dense, which lowers the sensitivity of mammography [6]. Women classified as either ACR-MG-a or ACR-MG-b are considered as having nondense breasts, whereas women with ACR-MG-c or ACRMG- $d$ are considered as having dense breasts. Moreover, there has been a change from the previous edition [23] to the revised 5 th edition of the BI-RADS atlas, from a percentage categorization of total breast density with quartiles $(<25 \% ; 25-49 \%$; $50-74 \%$; and $>75 \%$ ) to descriptive categories and coalescent areas on the mammogram to indicate possible masking of underlying breast masses (Fig. 1). This masking effect is one of the primary reasons for the decreased sensitivity of mammography in higher density categories introducing a potential benefit of supplemental screening [24•]. Many studies have shown significant inter- and intra-observer variability for subjective visual estimation of breast density/composition on mammography [25-27, 28••], which implies that qualitative assessment is a rather imperfect measure of breast density [29••].

To overcome the limitations of subjective visual assessments, computer-aided semi-automated and fully automated measurement approaches are now available and can be either a 2D area-based or 3D volumetric-based methods for assessing breast density. The most commonly used $2 \mathrm{D}$ technique that had been regarded as the gold standard is the semi-automated interactive thresholding technique Cumulus ${ }^{\mathrm{TM}}$, which was introduced by Byng et al. and allows separation of mammographic dense from fatty tissue, and thus calculates percentage mammographic density [30]. Cumulus ${ }^{\mathrm{TM}}$ has been used in numerous epidemiological studies and demonstrates a higher reproducibility compared to BI-RADS visual assessment [31]. A severe limitation of the interactive thresholding method is that it relies on 2D images and is heavily operator dependent. Meanwhile, 3D mammography-based breast density measurement systems have become available. Highnam et al. [32] and van Engeland et al. [33] have introduced approaches that calculate a quantity, referred to as the thickness of the examined fibroglandular tissue. To date, the Food and Drug Administration has approved Quantra and Volpara for mammography-based volumetric quantitative breast density measurements, which allow volumetric, quantitative measurements of the absolute breast tissue [26, 27, 34-36]. However, it must be noted that breast density calculations based on mammography may also vary due to tissue compression and breast positioning. 


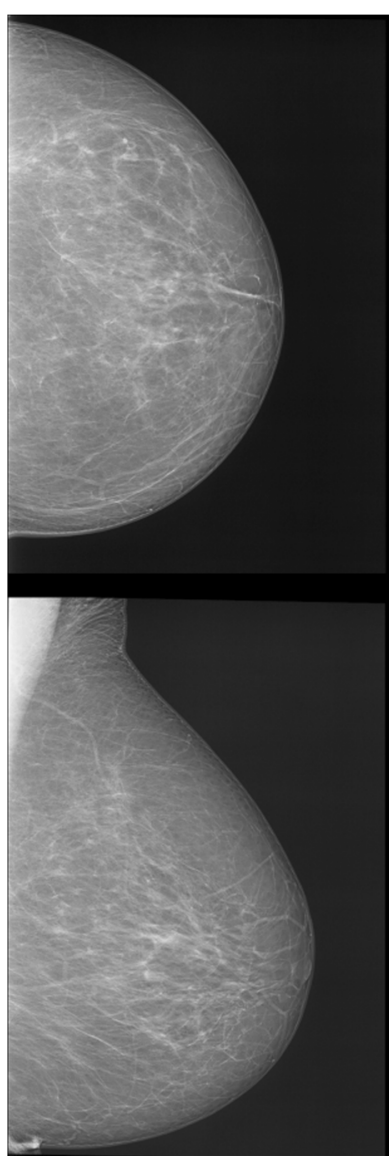

ACR MG-a

Fig. 1 Example images of the four breast density/composition categories defined by the 5th edition of the BI-RADS mammography atlas with descriptive categories indicating coalescent breast tissue with possible masking of underlying masses. ACR MG-a, the breasts are almost

\section{Ultrasound}

Ultrasound (US) of the breast is a ubiquitous and costeffective yet relatively operator-dependent imaging modality, which is easy to perform without the need for intravenous contrast application or ionizing radiation. To date, breast US cannot be reliably used for either a qualitative or quantitative assessment of breast density. However, the latest version of the US BI-RADS atlas recommends a classification of breast tissue composition with US in three descriptive categories: ACR-US-a, homogeneous background echotexture-fat; ACR-US-b, homogeneous background echotexturefibroglandular; and ACR-US-c, heterogeneous background echotexture [6]. To overcome the drawback of handheld US, automated 3D whole-breast US (ABUS) has been introduced [37] and attempts have been made also to assess breast density with 3D ABUS using semi-automated techniques $[38 \cdot, 39]$. Initial results suggest that ABUS might provide $3 \mathrm{D}$ volumetric imaging and accurate breast density

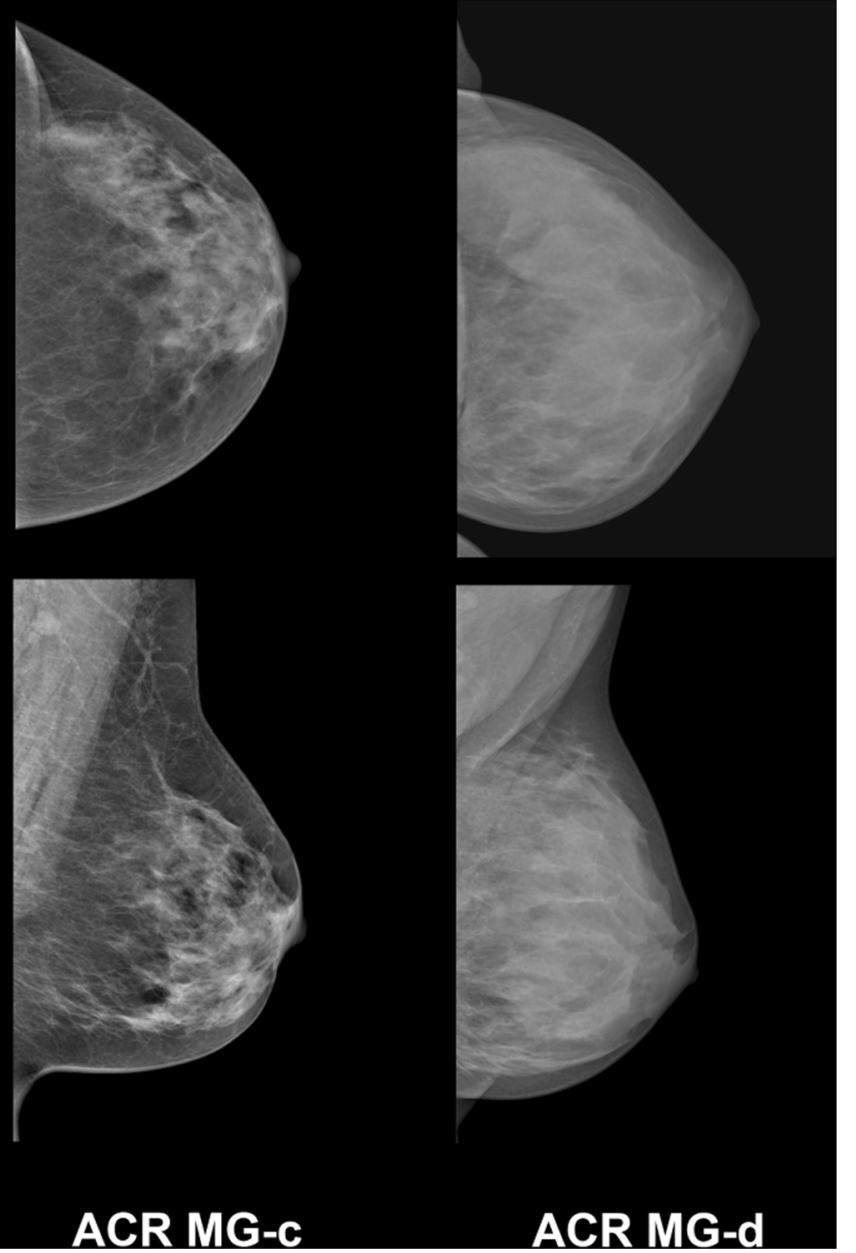

entirely fatty; ACR MG-b, there are scattered areas of fibroglandular density; ACR MG-c, the breasts are heterogeneously dense, which may obscure small masses; and ACR MG-d, the breasts are extremely dense, which lowers the sensitivity of mammography

measurement $[38 \cdot, 39]$. In asymptomatic women with dense breast US may be a supplemental screening modality adjunct to mammography to enable the detection of additional breast cancers invisible on mammography [40].

\section{Magnetic Resonance Imaging}

Breast density assessment with mammography requires the use of ionizing radiation and compression of the breast, which is often uncomfortable or even painful for the patient. Mammography is a 2D method assessing the breast, which is a $3 \mathrm{D}$ structure, and therefore is likely not to provide an accurate absolute, but rather a rough estimate. Additionally, except for R2 Quantra, Volpara, and Densitas, most of the other methods require interaction from radiologists. To address the problems of mammography-based breast density assessment, promising approaches of volumetric, quantitative assessment of the amount of fibroglandular tissue on magnetic resonance imaging (MRI) have been developed and tested. 
In contrast to mammography, MRI allows radiation- and compression-free 3D imaging of the breasts and is also able to include breast areas near the chest wall and axilla. MRI provides images related to the fat and water composition of the breast. Since the water composition is highly correlated with the prevalence of fibroglandular tissue, these images can be used for slice-by-slice segmentation of fibroglandular and fatty tissues for quantitative breast density assessment [41]. Many of the currently available approaches rely on the use of T1-weighted sequences, which provide gray-scale images and therefore not enough tissue contrast to allow an objective measurement of breast parenchyma. In addition, most of these approaches require user interaction for breast area segmentation or threshold adjustments [33, 42-47].

To allow precise segmentation, one of the most important steps is the exact definition of breast and tissue borders. The boundaries for the segmentation usually are the anterior border of the major pectoral muscle and the ventral chest wall. As cranial and caudal boundaries, the inferior border of the manubrium sterni and the submammary fold are chosen. For the definition of the lateral borders, Nie et al. [47] proposed an algorithm called the V-shaped cut, which is defined as the area between the lateral border of each major pectoralis muscle and the spinous process at the level of the aortic arch. However, depending on the field of view, the spinous process is not always within the acquired breast volume, and therefore, the $\mathrm{V}$-shaped cut is not always applicable. Moreover, preferentially, the variable subcutaneous fatty tissue of the cleavage should also be excluded from the segmentation. To overcome these, atlas- [48, 49] or template-aided [50] semi-automated approaches with predefined breast models and automated adaption in real time have been explored for individual breast segmentation and the individual outcomes have yielded high accuracy and robustness.

Besides semi-automated approaches, there are already fully automated, volumetric measurement approaches available to assess the amount of fibroglandular breast tissue on MRI. Gubern-Merida et al. [51] used an expectation-maximization algorithm based on fuzzy $C$-means clustering, and Wu et al. [49] developed a fully automated segmentation approach based on 2D $C$-means clustering. Wengert et al. introduced an iterative segmentation for the separation of the bivariate signal intensity values on Dixon sequences [50] (Fig. 2). The use of Dixon sequences for MRI-based measurements of the amount of fibroglandular tissue has been suggested previously [52] and tested with promising results [50, 53, 54]. Dixon sequences allowed improved reproducibility and accuracy of breast density measurements compared to conventional sequences $[55,56 \bullet]$. The integration of Dixon sequences into standard clinical MRI protocols for dynamic contrast-enhanced imaging, as well as fibroglandular tissue quantification, is easily possible $[55,57]$. Therefore, a recommendation for objective fibroglandular tissue segmentation derived from high-resolution Dixon sequences as the MRIbased reference standard for the assessment of the amount of FGT seems practicable [55, 57-59].

However, it must be pointed out that while fully automated, volumetric MRI-based measurement approaches provide percentage values of breast density, such values are currently not included in the 5 th edition of the BI-RADS lexicon. The MRI BI-RADS lexicon currently contains the recommendation to assess the amount of fibroglandular tissue with MRI similar to mammography with four classes (Fig. 3): ACR-MRI-a, almost entirely fat; ACR-MRI-b, scattered fibroglandular tissue; ACR-MRI-c, heterogeneous fibroglandular tissue; and ACRMRI-d, extreme fibroglandular tissue [6]. Recent studies have shown that this subjective visual estimation of breast density on mammography and the amount of FGT on MRI are prone to error with great inter- and intra-observer variability, which can be improved by reader training [28••, 60, 61]. Similar to mammography, this therefore seems suboptimal compared with objective assessment approaches [26, 27, 28••, 36, 62].

\section{Breast Density and the Risk for Breast Cancer}

Breast density impacts the risk for breast cancer in different ways:

- Breast density can mask breast cancer due to an overlap with normal breast, i.e., the masking effect reduces the sensitivity of mammography screening.

- Breast density is an independent risk factor for breast cancer.

\section{Masking Effect}

There is good evidence that the sensitivity of mammography decreases with increasing breast density. Increasing breast density leads to the effect of overlapping normal breast tissue resulting in coalescent areas of breast parenchyma and obliteration of tissue asymmetries and underlying tumors especially with 2D imaging modalities [6-8]. This masking effect contributes significantly to the reduced sensitivity of screening mammography [7, 8]. Larger breast tumors and advanced stages with lymphatic involvement are seen more often with higher density categories [63-65]. In addition, interval cancers are also increased with studies reporting a 6- to 17-fold increase in the risk of interval cancers for women with higher breast density categories $[12,13,66]$.

Most of the evidence on the reduced sensitivity of mammography in dense breasts is from studies that employed screen film mammography (SFM) [5, 6]. With the implementation of full-field digital mammography (FFDM), the sensitivity of screening mammography for cancer detection in 


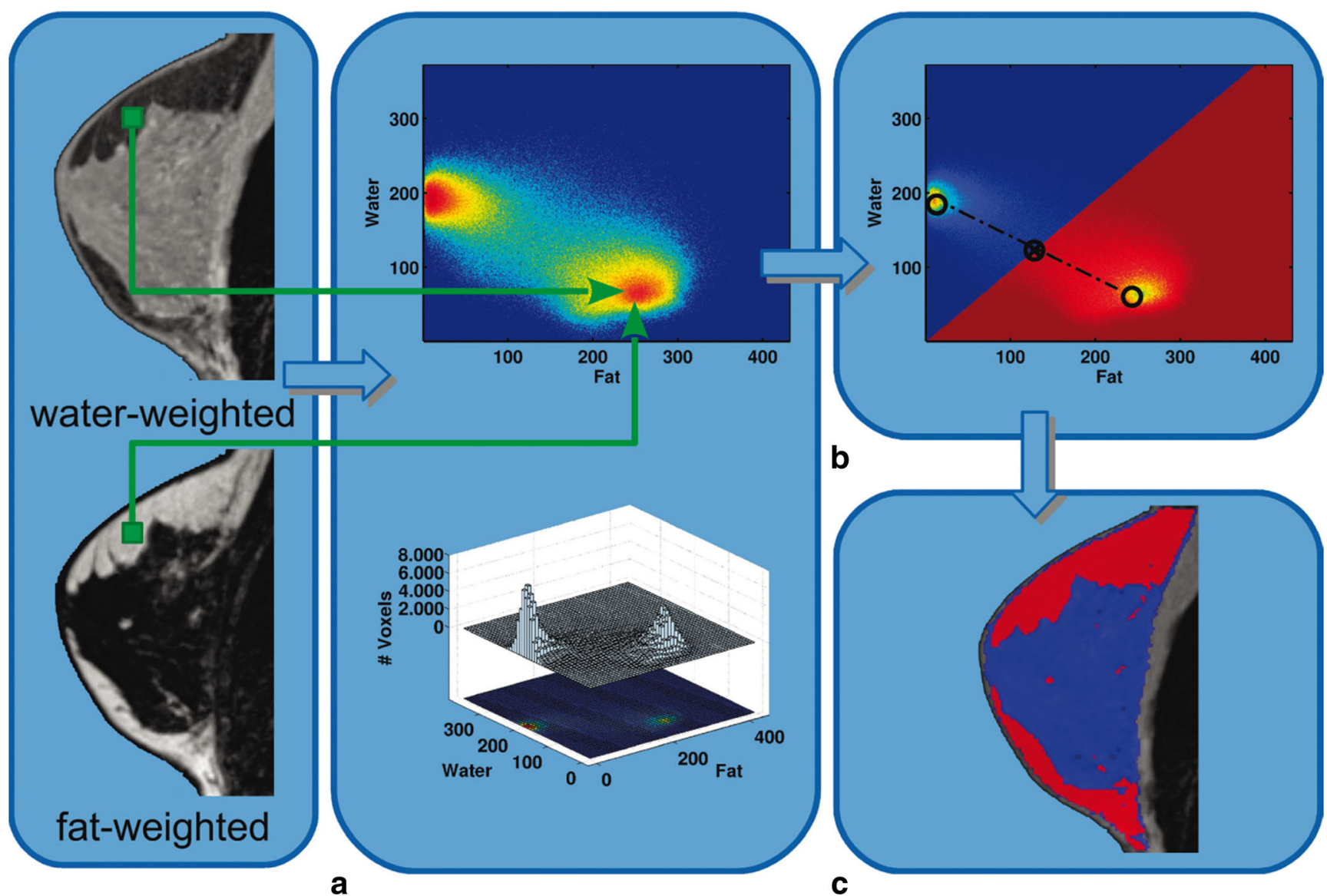

Fig. 2 Diagram of the process of fibroglandular tissue segmentation. For each individual breast and water-/fat-based sequence, the program automatically segments an individual breast model, representing the identical 3D breast volume, with the exclusion of the skin and the pectoralis muscle. (A) The signal intensity (SI) values of fat- and waterweighted pixel intensities were recorded and collected into a $2 \mathrm{D}$ histogram (top image). At the bottom, there is the 3D illustration of the histogram. (B) Thresholds for the corresponding fat and water SI values were automatically calculated by dividing the histogram into two regions half the distance between the two cluster peaks of the bimodal distribution of measured SI values. (C) Graphical illustration of the assignment for each voxel to be either fat tissue (red) or dense tissue (blue) into the 3D breast model. Published with permission from [50] https://insights.ovid. com/pubmed?pmid=25333307 women with higher density categories has significantly improved $[10,67]$. Data consistently indicate that with the use of FFDM compared with SFM, the masking effect of dense breasts on cancer detection is greatly reduced [10, 67]. In addition, Kerliwoske et al. [68] showed that FFDM compared with SFM also improves the detection of hormone receptornegative breast cancers (FFDM 78.5\% vs SFM 65.8\%, sensitivity $P=.016$, in women aged $40-79$ years; $95.2 \%$ vs $54.9 \%$, sensitivity, $P=.007$, in women aged $40-49$ years). These cancers are usually higher grade, carry a poorer prognosis and often manifest as interval cancers, and presumably constitute some proportion of the cancers masked at SFM screening in women with higher density categories.

Recently, digital breast tomosynthesis (DBT) has been implemented in breast imaging. Several large-scale studies worldwide that investigated DBT in the screening setting have demonstrated an increase in cancer detection as well as significant reduction in recall rates compared with FFDM, which is most likely attributable to a decreased masking effect [69-71].
However, the effect of DBT on breast cancer detection related to breast density is not clear yet. In the STORM trial, Ciatto et al. noted that the incremental cancer detection rate beyond that of FFDM in women screened with combined DBT and mammography was similar for dense and non-dense breasts (2.5 per 1000 vs 2.8 per 1000 , respectively) [72]. Further studies will be necessary to provide specific insights into the benefits of DBT for reducing the masking effect in women with higher density.

An additional supplemental screening tool in women with higher density is the whole-breast ultrasound (ABUS). Although there is an incremental cancer detection rate with ABUS beyond that of mammography, this comes at the expense of higher false-positive rates with a $\mathrm{PPV}_{3}$ reported as low as $3.2 \%$ [40, 73-76]. The Institute for Clinical and Economic Review (ICER) report on "The Comparative Clinical Effectiveness and Value of Supplemental Screening Tests Following Negative Mammography in Women with Dense Breast Tissue" [77••] surmised from the results from 


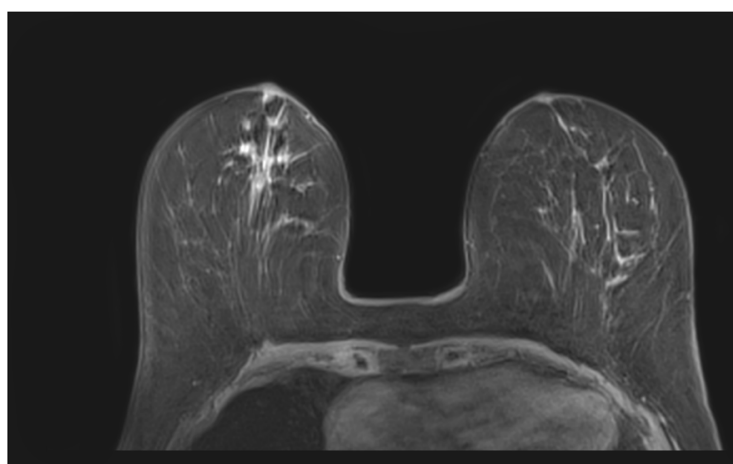

ACR MRI-a

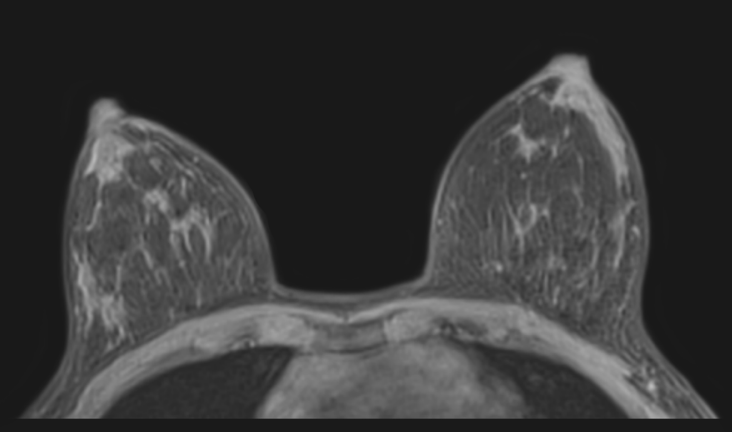

ACR MRI-b

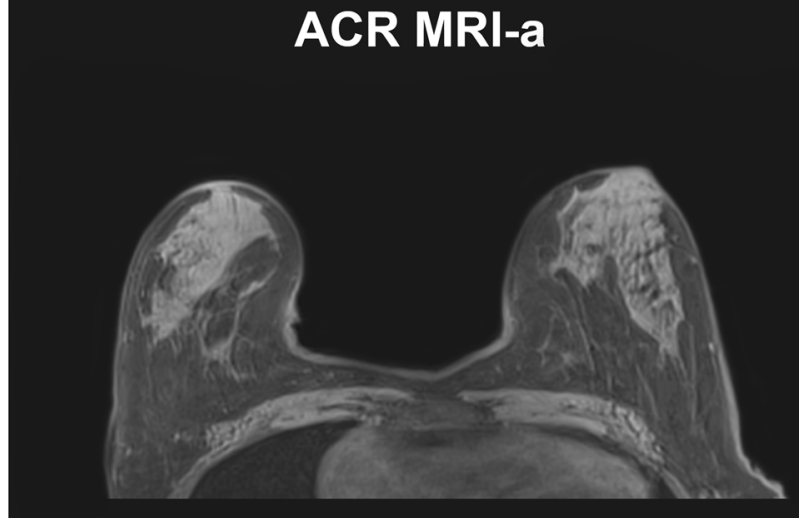

ACR MRI-C

Fig. 3 Example images of the four breast density/composition categories defined by the 5th edition of the BI-RADS MRI atlas with four categories similar to mammography. ACR MRI-a, almost entirely fat; ACR MRI-b,
15 studies as well as the results of the ACRIN 6666 study [78]. The reported appropriate estimate for the incremental cancer detection rate with supplemental whole-breast screening US is 2 to 3 per 1000, with a markedly low $\mathrm{PPV}_{3}$ of 6-7\%. Initial results with ABUS screening in women with dense breast are promising. The addition of ABUS to mammography resulted in the detection of 12.3 per 1000 breast cancers, compared to 4.6 per 1000 by mammography alone [79]. However, the true potential of ABUS in this setting still remains to be fully explored.

To date, there is no data available on the benefits of supplemental screening with MRI in women with higher breast density categories. The American Cancer Society (ACS) guidelines neither recommend for nor against screening MRI in women with the risk factor of a higher breast density [80-82]. Screening with MRI is currently reserved for women with a lifetime risk of $>20 \%$ [80] and has proven to be superior to both mammography and US for breast cancer detection [83-85]. The Dutch DENSE trial investigates the effectiveness and cost-effectiveness of screening with mammography and MRI compared with those of screening with mammography alone in women with extremely dense breasts [86]. The study has finished enrolment, and the results are eagerly anticipated to better define the role of MRI in this patient population. At this time, the value of supplemental breast MRI screening in women with higher breast density categories remains unclear, and currently, there is no evidence supporting its use.

\section{Independent Risk Factor}

Although the masking effect of breast cancer in dense breast is important, breast density is also an independent risk factor for breast cancer $[13,15,87,88]$. Breast density refers to epithelial and glandular structures in the breast that are the origin of most breast cancers. It therefore seems logical that an increased breast density elevates the chances of developing breast cancer, i.e., the more epithelial tissue, the greater the chance that cancer may arise in one of the epithelial cells [89].

There is debate as to what extent breast density constitutes an independent risk factor for breast cancer, yet numerous studies have demonstrated an association between breast density and risk for breast cancer that is more than merely a masking bias and cannot be explained by the reduced sensitivity of mammography alone.

In the literature, it has been reported that a linear increase in breast density is associated with a four- to sixfold increase in the risk of breast cancer [31]. In a meta-analysis by 
McCormack et al. that investigated breast density as an independent risk factor for breast cancer, the relative risk associated with dense breasts was 2.92 for breasts that were $50-74 \%$ dense and 4.64 for breasts that were $75 \%$ or more dense [13]. Boyd et al. summarized studies that evaluated breast cancer risk with respect to quantitatively measured tissue density, and the odds ratio of the risk for breast cancer ranged from 3.6 to 6.0 [31]. It must be pointed out that the majority of the studies that investigated the associations of breast cancer risk and breast density did not use the ACR BI-RADS categories but quantitative measures or different classification such as the Wolfe classification. It has been demonstrated that the use of the BI-RADS classification results in a similar but milder association of risk with breast density [89].

In many of the studies published on the associations of the relative risk of breast cancer with mammographic density, women with almost entirely fatty breast were compared with women with extremely dense breast. As only approximately $10 \%$ of women have either extremely dense or almost entirely fatty breasts, the results are potentially misleading. Nevertheless, when comparing the relative risk for cancer in women with dense breasts to the risk in the average patient, i.e., a tissue density approximately halfway between the two middle categories of scattered areas of fibroglandular density and heterogeneously dense, the relative risk in women with heterogeneously dense breasts compared with the average woman is approximately 1.2 and in women with extremely dense breasts compared with the average woman approximately 2.1 .

Although the relative risk of breast density is much smaller than that of other major risk factors for breast cancer, such as age, family history, reproductive history, and genetic mutations, breast density is still a risk factor. Breast density can be easily assessed with mammography, and mammographically dense breasts are relatively common (approximately $50 \%$ of the screening population). It therefore stands to reason that the risk factor of breast density alone contributes far more cancer risk to the population than other much stronger risk factors that are less common, such as BRCA mutations or high-risk status $[13,31,89]$.

Efforts have also been made to investigate the correlation of breast cancer risk with the amount of fibroglandular tissue on MRI. King et al. investigated the relationships between breast cancer and the amount of fibroglandular tissue and level of background parenchymal enhancement (BPE) on MRI [90]. They found that breast cancer odds ratio increased significantly with increasing BPE. Odds ratio also increased with increasing fibroglandular tissue, but the BPE findings remained significant after adjustment for fibroglandular tissue. Dontchos et al. investigate whether qualitative MRI assessments of BPE, fibroglandular tissue, and mammographic breast density are associated with the risk of developing breast cancer in high-risk women [91]. In this study, greater BPE was associated with a higher probability of developing breast cancer. However, there was no significant association between fibroglandular tissue or mammographic breast density and cancer development $(P=.5$ and $P=.4)$. Initial data indicate that with MRI, BPE might a more valuable imaging biomarker for breast cancer risk than fibroglandular tissue. However further studies are warranted to confirm these findings.

\section{Conclusion}

Breast density has become an important topic in breast imaging. Breast density impacts the risk for breast cancer in different ways. On one hand, breast density reduces the sensitivity of mammography due to a masking effect, and on the other hand, there is evidence that breast density is an independent risk factor for breast cancer. Although the extent to which it is an independent risk factor remains controversial, there is a consensus that the increased breast cancer risk is not solely attributable to the masking effect [89]. This emphasizes the potential of breast density for risk prediction and stratification and that breast density might become a valuable tool in determining the best screening plan for each woman and to guide supplemental screening methods. However, to be used in this context, breast density assessment must be reliable, reproducible, and accurate. Breast density has been mainly assessed with mammography using qualitatively subjective visual inspection via the ACR BI-RADS classification. Due to substantial intra-/inter-reader variability, semi-/automated volumetric breast density measurement approaches with both mammography and MRI have been developed with excellent results. Initial attempts for automated volumetric breast density measurements with ABUS are promising. It is expected that these advances in breast density assessment will further define its role in breast cancer risk assessment and help to tailor breast cancer screening strategies to an individual woman's risk, values, and preferences while also accounting for cost, potential harms, and patient-important outcomes.

Acknowledgments This study was funded in part through the NIH/NCI Cancer Center Support Grant P30 CA008748.

Funding Information Funding Information Open access funding provided by Medical University of Vienna. Funding was provided by the Austrian Nationalbank "Jubiläumsfond" Project Nr. 16219, Nr. 15082, the 2020 Research and Innovation Framework Programme PHC-11-2015 Nr. 667211-2, and seed grants from Siemens Austria, Novomed, Medicor Austria, and Guerbet France.

\section{Compliance with Ethical Standards}

Conflict of Interest Georg Wengert, Thomas Helbich, Doris Leithner, Elizabeth Morris, Pascal Baltzer, and Katja Pinker declare that they have no conflicts of interest. 
Human and Animal Rights and Informed Consent This article does not contain any studies with human or animal subjects performed by any of the authors.

Open Access This article is distributed under the terms of the Creative Commons Attribution 4.0 International License (http:// creativecommons.org/licenses/by/4.0/), which permits unrestricted use, distribution, and reproduction in any medium, provided you give appropriate credit to the original author(s) and the source, provide a link to the Creative Commons license, and indicate if changes were made.

Publisher's Note Springer Nature remains neutral with regard to jurisdictional claims in published maps and institutional affiliations.

\section{References}

Papers of particular interest, published recently, have been highlighted as:

- Of importance

-• Of major importance

1. Boyd NF, Martin LJ, Yaffe MJ, Minkin S. Mammographic density: a hormonally responsive risk factor for breast cancer. J Br Menopause Soc. 2006;12(4):186-93. https://doi.org/10.1258/ 136218006779160436.

2. Sterns EE, Zee B. Mammographic density changes in perimenopausal and postmenopausal women: is effect of hormone replacement therapy predictable? Breast Cancer Res Treat. 2000;59(2): $125-32$.

3. van Duijnhoven FJ, Peeters PH, Warren RM, Bingham SA, van Noord PA, Monninkhof EM, et al. Postmenopausal hormone therapy and changes in mammographic density. J Clin Oncol. 2007;25(11):1323-8.

4. Byrne C, Ursin G, Martin CF, Peck JD, Cole EB, Zeng D et al. Mammographic density change with estrogen and progestin therapy and breast cancer risk. J Natl Cancer Inst. 2017;109(9). doi: https://doi.org/10.1093/jnci/djx001.

5. Price ER, Hargreaves J, Lipson JA, Sickles EA, Brenner RJ, Lindfors KK, et al. The California breast density information group: a collaborative response to the issues of breast density, breast cancer risk, and breast density notification legislation. Radiology. 2013;269(3):887-92. https://doi.org/10.1148/radiol.13131217.

6. D’Orsi CJSE, Mendelson EB, Morris EA. ACR BI-RADS® atlas, breast imaging reporting and data system. Reston, VA: American College of Radiology; 2013.

7. Jackson VP, Hendrick RE, Feig SA, Kopans DB. Imaging of the radiographically dense breast. Radiology. 1993;188(2):297-301. https://doi.org/10.1148/radiology.188.2.8327668.

8. Rhodes DJ, Radecki Breitkopf C, Ziegenfuss JY, Jenkins SM, Vachon CM. Awareness of breast density and its impact on breast cancer detection and risk. J Clin Oncol. 2015;33:1143-50. https:// doi.org/10.1200/JCO.2014.57.0325.

9. Bailey SL, Sigal BM, Plevritis SK. A simulation model investigating the impact of tumor volume doubling time and mammographic tumor detectability on screening outcomes in women aged 40-49 years. J Natl Cancer Inst. 2010;102(16):1263-71. https://doi.org/ 10.1093/jnci/djq271.

10. Carney PA, Miglioretti DL, Yankaskas BC, Kerlikowske K, Rosenberg R, Rutter CM, et al. Individual and combined effects of age, breast density, and hormone replacement therapy use on the accuracy of screening mammography. Ann Intern Med. 2003;138(3):168-75.

11. Ballard-Barbash R, Taplin SH, Yankaskas BC, Ernster VL, Rosenberg RD, Carney PA, et al. Breast Cancer Surveillance Consortium: a national mammography screening and outcomes database. AJR Am J Roentgenol. 1997;169(4):1001-8. https:// doi.org/10.2214/ajr.169.4.9308451.

12. Boyd NF, Guo H, Martin LJ, Sun L, Stone J, Fishell E, et al. Mammographic density and the risk and detection of breast cancer. N Engl J Med. 2007;356(3):227-36. https://doi.org/10.1056/ NEJMoa062790.

13. McCormack VA, dos Santos Silva I. Breast density and parenchymal patterns as markers of breast cancer risk: a meta-analysis. Cancer Epidemiol Biomark Prev. 2006;15(6):1159-69. https://doi. org/10.1158/1055-9965.EPI-06-0034.

14. Kerlikowske K, Ichikawa L, Miglioretti DL, Buist DS, Vacek PM, Smith-Bindman R, et al. Longitudinal measurement of clinical mammographic breast density to improve estimation of breast cancer risk. J Natl Cancer Inst. 2007;99(5):386-95. https://doi.org/10. 1093/jnci/djk066.

15. Boyd NF, Martin LJ, Bronskill M, Yaffe MJ, Duric N, Minkin S. Breast tissue composition and susceptibility to breast cancer. J Natl Cancer Inst. 2010;102(16):1224-37. https://doi.org/10.1093/jnci/ djq239.

16. Huo CW, Chew GL, Britt KL, Ingman WV, Henderson MA, Hopper JL, et al. Mammographic density-a review on the current understanding of its association with breast cancer. Breast Cancer Res Treat. 2014;144(3):479-502. https://doi.org/10.1007/s10549014-2901-2.

17. Santen RJ, Boyd NF, Chlebowski RT, Cummings S, Cuzick J, Dowsett M, et al. Critical assessment of new risk factors for breast cancer: considerations for development of an improved risk prediction model. Endocr Relat Cancer. 2007;14(2):169-87. https://doi. org/10.1677/ERC-06-0045.

18. American College of Radiology A. Breast Density Mandates Spread State to State. 2018. https://www.acr.org/Advocacy-andEconomics/Advocacy-News/Advocacy-News-Issues/In-the-April14-2018-Issue/Breast-Density-Mandates-Spread-State-to-State. Accessed 29 Nov 2018. Official homepage, published by the American College of Radiology, that provides information on how many and in particular which states of the US have passed breast density notification laws with the intention to inform women about their own breast density status and the inherent risk of breast density.

19. Winkler NS, Raza S, Mackesy M, Birdwell RL. Breast density: clinical implications and assessment methods. Radiographics. 2015;35(2):316-24. https://doi.org/10.1148/rg.352140134.

20. Colin C, Schott AM, Valette PJ. Mammographic density is not a worthwhile examination to distinguish high cancer risk women in screening. Eur Radiol. 2014;24(10):2412-6. https://doi.org/10. 1007/s00330-014-3278-7.

21. Wolfe JN. Breast patterns as an index of risk for developing breast cancer. AJR Am J Roentgenol. 1976;126(6):1130-7. https://doi. org/10.2214/ajr.126.6.1130.

22. He W, Hogg P, Juette A, Denton ER, Zwiggelaar R. Breast image pre-processing for mammographic tissue segmentation. Comput Biol Med. 2015;67:61-73. https://doi.org/10.1016/j.compbiomed. 2015.10.002.

23. D’Orsi CJBL, Feig SA, Jackson VP, Kopans DB, Linver MN, Sickles EA, et al. Breast imaging reporting and data system: ACR BI-RADS - breast imaging atlas. 4th ed. American College of Radiology: Reston, VA; 2003.

24. van der Waal D, Ripping TM, Verbeek AL, Broeders MJ. Breast cancer screening effect across breast density strata: a case-control study. Int J Cancer. 2017;140(1):41-9. https://doi.org/10.1002/ijc. 30430 Recently published case-control study on the basis of a 
Dutch screening program over a duration of 33 years revealed a poorer screening performance in dense breast tissue compared to fatty breasts (sensitivity $\mathbf{5 7 . 8 \%}$ vs $\mathbf{7 5 . 7 \%}$ ). Mortality reduction was smaller in denser breasts compared to fatty breasts (OR 0.87 vs 0.59 ). The authors concluded that a poorer screening performance and smaller mortality reduction is observed in higher breast density highlighting the potential of breast density for risk-stratification.

25. Ciatto S, Bernardi D, Calabrese M, Durando M, Gentilini MA, Mariscotti G, et al. A first evaluation of breast radiological density assessment by QUANTRA software as compared to visual classification. Breast. 2012;21(4):503-6. https://doi.org/10.1016/j.breast. 2012.01.005.

26. Lee HN, Sohn YM, Han KH. Comparison of mammographic density estimation by Volpara software with radiologists' visual assessment: analysis of clinical-radiologic factors affecting discrepancy between them. Acta Radiol. 2014;56:1061-8. https://doi.org/10. $1177 / 0284185114554674$

27. Morrish OW, Tucker L, Black R, Willsher P, Duffy SW, Gilbert FJ. Mammographic breast density: comparison of methods for quantitative evaluation. Radiology. 2015;141508:356-65. https://doi.org/ 10.1148/radiol.14141508.

28.• Wengert GJ, Helbich TH, Woitek R, Kapetas P, Clauser P, Baltzer $\mathrm{PA}$, et al. Inter- and intra-observer agreement of BI-RADS-based subjective visual estimation of amount of fibroglandular breast tissue with magnetic resonance imaging: comparison to automated quantitative assessment. European radiology. 2016. https://doi.org/ 10.1007/s00330-016-4274-x First study that addresses the interand intra-reader agreement of BI-RADS based subjective visual assessment of the amount of fibroglandular tissue with magnetic resonance imaging, as recommended by the actual BIRADS lexicon. The findings showed that automated userindependent measurements are necessary to allow reliable and standardized risk evaluation in contrast to high inconsistency of subjective visual assessments.

29.• Osteras BH, Martinsen AC, Brandal SH, Chaudhry KN, Eben E, Haakenaasen U, et al. Classification of fatty and dense breast parenchyma: comparison of automatic volumetric density measurement and radiologists' classification and their inter-observer variation. Acta Radiol. 2016. https://doi.org/10.1177/0284185115626469 Inter-observer study of subjective BI-RADS based breast density assessment on mammography compared to volumetric and automated measurements (Quantra). The results of the automated measurements showed substantial accuracy and consistency compared to the subjective BI-RADS based assessments with a high inter-observer variability.

30. Byng JW, Boyd NF, Fishell E, Jong RA, Yaffe MJ. The quantitative analysis of mammographic densities. Phys Med Biol. 1994;39(10): 1629-38.

31. Boyd NF, Martin LJ, Yaffe MJ, Minkin S. Mammographic density and breast cancer risk: current understanding and future prospects. Breast Cancer Res. 2011;13(6):223. https://doi.org/10.1186/ bcr2942.

32. Highnam R, Jeffreys M, McCormack V, Warren R, Davey Smith G, Brady M. Comparing measurements of breast density. Phys Med Biol. 2007;52(19):5881-95. https://doi.org/10.1088/0031-9155/52/ $19 / 010$.

33. van Engeland S, Snoeren PR, Huisman H, Boetes C, Karssemeijer N. Volumetric breast density estimation from full-field digital mammograms. IEEE Trans Med Imaging. 2006;25(3):273-82. https:// doi.org/10.1109/TMI.2005.862741.

34. Brand JS, Czene K, Shepherd JA, Leifland K, Heddson B, Sundbom A, et al. Automated measurement of volumetric mammographic density: a tool for widespread breast cancer risk assessment. Cancer Epidemiol, Biomark Prev. 2014;23(9):1764-72. https://doi.org/10.1158/1055-9965.EPI-13-1219.
35. Brandt KR, Scott CG, Ma L, Mahmoudzadeh AP, Jensen MR, Whaley DH, et al. Comparison of clinical and automated breast density measurements: implications for risk prediction and supplemental screening. Radiology. 2015;151261:710-9. https://doi.org/ 10.1148/radiol.2015151261.

36. Wang J, Azziz A, Fan B, Malkov S, Klifa C, Newitt D, et al. Agreement of mammographic measures of volumetric breast density to MRI. PLoS One. 2013;8(12):e81653. https://doi.org/10. 1371/journal.pone.0081653.

37. Chae EY, Shin HJ, Kim HJ, Yoo H, Baek S, Cha JH, et al. Diagnostic performance of automated breast ultrasound as a replacement for a hand-held second-look ultrasound for breast lesions detected initially on magnetic resonance imaging. Ultrasound Med Biol. 2013;39(12):2246-54. https://doi.org/10.1016/j. ultrasmedbio.2013.07.005.

38. Chen JH, Lee YW, Chan SW, Yeh DC, Chang RF. Breast Density Analysis with Automated Whole-Breast Ultrasound: Comparison with 3-D Magnetic Resonance Imaging. Ultrasound Med Biol. 2016;42(5):1211-20. https://doi.org/10.1016/j.ultrasmedbio.2015. 12.015 Ultrasound of the breast, as well as 3D automated whole-breast ultrasound (ABUS) and magnetic resonance imaging (MRI) of the breast in comparison to mammography or tomosynthesis provide true volumetric information to perform accurate density estimation. Although some promising attempts have been published, the use of ABUS for breast density assessment is rather unknown. This recently published study compared semi-automated measurement techniques of breast density assessment with ABUS compared to MRI and showed a high correlation between both modalities. Therefore, ABUS can contribute to a reliable breast density assessment.

39. Moon WK, Shen YW, Huang CS, Luo SC, Kuzucan A, Chen JH, et al. Comparative study of density analysis using automated whole breast ultrasound and MRI. Med Phys. 2011;38(1):382-9. https:// doi.org/10.1118/1.3523617.

40. Houssami N, Ciatto $\mathrm{S}$. The evolving role of new imaging methods in breast screening. Prev Med. 2011;53(3):123-6. https://doi.org/ 10.1016/j.ypmed.2011.05.003.

41. O'Flynn EA, Ledger AE, de Souza NM. Alternative screening for dense breasts: MRI. AJR Am J Roentgenol. 2015;204(2):W141-9. https://doi.org/10.2214/AJR.14.13636.

42. Klifa C, Carballido-Gamio J, Wilmes L, Laprie A, Lobo C, Demicco E, et al. Quantification of breast tissue index from MR data using fuzzy clustering. Conf Proc IEEE Eng Med Biol Soc. 2004;3:1667-70. https://doi.org/10.1109/IEMBS.2004.1403503.

43. Klifa C, Carballido-Gamio J, Wilmes L, Laprie A, Shepherd J, Gibbs J, et al. Magnetic resonance imaging for secondary assessment of breast density in a high-risk cohort. Magn Reson Imaging. 2010;28(1):8-15. https://doi.org/10.1016/j.mri.2009.05.040.

44. Lee NA, Rusinek H, Weinreb J, Chandra R, Toth H, Singer C, et al. Fatty and fibroglandular tissue volumes in the breasts of women 20-83 years old: comparison of X-ray mammography and computer-assisted MR imaging. AJR Am J Roentgenol. 1997;168(2):501-6. https://doi.org/10.2214/ajr.168.2.9016235.

45. Thompson DJ, Leach MO, Kwan-Lim G, Gayther SA, Ramus SJ, Warsi I, et al. Assessing the usefulness of a novel MRI-based breast density estimation algorithm in a cohort of women at high genetic risk of breast cancer: the UK MARIBS study. Breast Cancer Res. 2009;11(6):R80. https://doi.org/10.1186/bcr2447.

46. Nie K, Chang D, Chen JH, Hsu CC, Nalcioglu O, Su MY. Quantitative analysis of breast parenchymal patterns using 3D fibroglandular tissues segmented based on MRI. Med Phys. 2010;37(1):217-26.

47. Nie K, Chen JH, Chan S, Chau MK, Yu HJ, Bahri S, et al. Development of a quantitative method for analysis of breast density based on three-dimensional breast MRI. Med Phys. 2008;35(12): 5253-62. 
48. Gubern-Merida A, Kallenberg M, Mann RM, Marti R, Karssemeijer N. Breast segmentation and density estimation in breast MRI: a fully automatic framework. IEEE J Biomed Health Inform. 2015;19(1):349-57. https://doi.org/10.1109/JBHI.2014. 2311163.

49. Wu S, Weinstein SP, Conant EF, Kontos D. Automated fibroglandular tissue segmentation and volumetric density estimation in breast MRI using an atlas-aided fuzzy C-means method. Med Phys. 2013;40(12):122302. https://doi.org/10.1118/1. 4829496.

50. Wengert GJ, Helbich TH, Vogl WD, Baltzer P, Langs G, Weber M, et al. Introduction of an automated user-independent quantitative volumetric magnetic resonance imaging breast density measurement system using the Dixon sequence: comparison with mammographic breast density assessment. Investig Radiol. 2015;50(2):7380. https://doi.org/10.1097/RLI.0000000000000102.

51. Gubern-Merida A, Kallenberg M, Platel B, Mann RM, Marti R, Karssemeijer N. Volumetric breast density estimation from fullfield digital mammograms: a validation study. PLoS One. 2014;9(1):e85952. https://doi.org/10.1371/journal.pone.0085952.

52. Graham SJ, Stanchev PL, Lloyd-Smith JO, Bronskill MJ, Plewes DB. Changes in fibroglandular volume and water content of breast tissue during the menstrual cycle observed by MR imaging at $1.5 \mathrm{~T}$. J Magn Reson Imaging. 1995;5(6):695-701.

53. Tagliafico A, Bignotti B, Tagliafico G, Astengo D, Martino L, Airaldi S, et al. Breast density assessment using a 3T MRI system: comparison among different sequences. PLoS One. 2014;9(6): e99027. https://doi.org/10.1371/journal.pone.0099027.

54. Tagliafico A, Tagliafico G, Astengo D, Airaldi S, Calabrese M, Houssami N. Comparative estimation of percentage breast tissue density for digital mammography, digital breast tomosynthesis, and magnetic resonance imaging. Breast Cancer Res Treat. 2013;138(1):311-7. https://doi.org/10.1007/s10549-013-2419-z.

55. Wengert GJ, Pinker-Domenig K, Helbich TH, Vogl WD, Clauser P, Bickel $\mathrm{H}$, et al. Influence of fat-water separation and spatial resolution on automated volumetric MRI measurements of fibroglandular breast tissue. NMR Biomed. 2016;29:702-8. https://doi.org/10. 1002/nbm.3516.

56. Wengert GJ, Pinker K, Helbich TH, Vogl WD, Spijker SM, Bickel $\mathrm{H}$, et al. Accuracy of fully automated, quantitative, volumetric measurement of the amount of fibroglandular breast tissue using MRI: correlation with anthropomorphic breast phantoms. NMR Biomed. 2017. https://doi.org/10.1002/nbm.3705 This study focused automated measurements of FGT with MRI using T1weighted and Dixon sequences based on known fractions of adipose and glandular components. The results showed the highest measurement correlation and reproducibility with Dixon sequences, indicating a Dixon based sequence protocol for recommended automated measurements of FGT with MRI in the near future.

57. Kuhl CK, Schrading S, Strobel K, Schild HH, Hilgers RD, Bieling HB. Abbreviated breast magnetic resonance imaging (MRI): first postcontrast subtracted images and maximum-intensity projection-a novel approach to breast cancer screening with MRI. J Clin Oncol. 2014;32(22):2304-10. https://doi.org/10.1200/JCO.2013.52.5386.

58. Mann RM, Mus RD, van Zelst J, Geppert C, Karssemeijer N, Platel B. A novel approach to contrast-enhanced breast magnetic resonance imaging for screening: high-resolution ultrafast dynamic imaging. Investig Radiol. 2014;49(9):579-85. https://doi.org/10. 1097/RLI.0000000000000057.

59. Clauser P, Pinker K, Helbich TH, Kapetas P, Bernathova M, Baltzer PA. Fat saturation in dynamic breast MRI at 3 tesla: is the Dixon technique superior to spectral fat saturation? A visual grading characteristics study. Eur Radiol. 2014;24(9):2213-9. https://doi.org/10. 1007/s00330-014-3189-7.
60. Raza S, Mackesy MM, Winkler NS, Hurwitz S, Birdwell RL. Effect of training on qualitative mammographic density assessment. J Am Coll Radiol. 2016;13(3):310-5. https://doi.org/10.1016/j.jacr.2015. 10.025 .

61. Gao J, Warren R, Warren-Forward H, Forbes JF. Reproducibility of visual assessment on mammographic density. Breast Cancer Res Treat. 2008;108(1):121-7. https://doi.org/10.1007/s10549-0079581-0.

62. Ciatto S, Houssami N, Apruzzese A, Bassetti E, Brancato B, Carozzi F, et al. Categorizing breast mammographic density: intra- and interobserver reproducibility of BI-RADS density categories. Breast. 2005;14(4):269-75. https://doi.org/10.1016/j.breast. 2004.12.004.

63. Ghosh K, Brandt KR, Sellers TA, Reynolds C, Scott CG, Maloney $\mathrm{SD}$, et al. Association of mammographic density with the pathology of subsequent breast cancer among postmenopausal women. Cancer Epidemiol, Biomark Prev. 2008;17(4):872-9. https://doi. org/10.1158/1055-9965.EPI-07-0559.

64. Aiello EJ, Buist DS, White E, Porter PL. Association between mammographic breast density and breast cancer tumor characteristics. Cancer Epidemiol Biomark Prev. 2005;14(3):662-8. https:// doi.org/10.1158/1055-9965.EPI-04-0327.

65. Roubidoux MA, Bailey JE, Wray LA, Helvie MA. Invasive cancers detected after breast cancer screening yielded a negative result: relationship of mammographic density to tumor prognostic factors. Radiology. 2004;230(1):42-8. https://doi.org/10.1148/radiol. 2301020589.

66. Mandelson MT, Oestreicher N, Porter PL, White D, Finder CA, Taplin SH, et al. Breast density as a predictor of mammographic detection: comparison of interval- and screen-detected cancers. J Natl Cancer Inst. 2000;92(13):1081-7.

67. Pisano ED, Gatsonis CA, Yaffe MJ, Hendrick RE, Tosteson AN, Fryback DG, et al. American College of Radiology Imaging Network digital mammographic imaging screening trial: objectives and methodology. Radiology. 2005;236(2):404-12. https://doi.org/ 10.1148/radiol.2362050440.

68. Kerlikowske K, Hubbard RA, Miglioretti DL, Geller BM, Yankaskas BC, Lehman CD, et al. Comparative effectiveness of digital versus film-screen mammography in community practice in the United States: a cohort study. Ann Intern Med. 2011;155(8): 493-502. https://doi.org/10.7326/0003-4819-155-8-20111018000005.

69. Destounis SV, Morgan R, Arieno A. Screening for dense breasts: digital breast tomosynthesis. AJR Am J Roentgenol. 2015;204(2): 261-4. https://doi.org/10.2214/AJR.14.13554.

70. Friedewald SM, Rafferty EA, Rose SL, Durand MA, Plecha DM, Greenberg JS, et al. Breast cancer screening using tomosynthesis in combination with digital mammography. JAMA. 2014;311(24): 2499-507. https://doi.org/10.1001/jama.2014.6095.

71. McDonald ES, Oustimov A, Weinstein SP, Synnestvedt MB, Schnall M, Conant EF. Effectiveness of digital breast tomosynthesis compared with digital mammography: outcomes analysis from 3 years of breast cancer screening. JAMA Oncol. 2016;2(6):737-43. https://doi.org/10.1001/jamaoncol.2015.5536.

72. Ciatto S, Houssami N, Bernardi D, Caumo F, Pellegrini M, Brunelli $\mathrm{S}$, et al. Integration of $3 \mathrm{D}$ digital mammography with tomosynthesis for population breast-cancer screening (STORM): a prospective comparison study. lancet Oncol. 2013;14(7):583-9. https://doi. org/10.1016/S1470-2045(13)70134-7.

73. Hooley RJ, Greenberg KL, Stackhouse RM, Geisel JL, Butler RS, Philpotts LE. Screening US in patients with mammographically dense breasts: initial experience with Connecticut Public Act 0941. Radiology. 2012;265(1):59-69. https://doi.org/10.1148/radiol. 12120621.

74. Tagliafico AS, Calabrese M, Mariscotti G, Durando M, Tosto S, Monetti F, et al. Adjunct screening with tomosynthesis or 
ultrasound in women with mammography-negative dense breasts: interim report of a prospective comparative trial. J Clin Oncol. 2016;34:1882-8. https://doi.org/10.1200/JCO.2015.63.4147.

75. Berg WA, Blume JD, Cormack JB, Mendelson EB, Lehrer D, Bohm-Velez M, et al. Combined screening with ultrasound and mammography vs mammography alone in women at elevated risk of breast cancer. JAMA. 2008;299(18):2151-63. https://doi.org/10. 1001/jama.299.18.2151.

76. Berg WA, Zhang Z, Lehrer D, Jong RA, Pisano ED, Barr RG, et al. Detection of breast cancer with addition of annual screening ultrasound or a single screening MRI to mammography in women with elevated breast cancer risk. JAMA. 2012;307(13):1394-404. https://doi.org/10.1001/jama.2012.388.

77.• Melnikow J, Fenton JJ, Whitlock EP, Miglioretti DL, Weyrich MS, Thompson JH, et al. Supplemental sScreening for breast cancer in women with dense breasts: a systematic review for the U.S. Preventive Services Task Force. Annals of internal medicine. 2016;164(4):268-78. https://doi.org/10.7326/M15-1789 This review focused on the reproducibility of subjective BI-RADS based breast density assessments and tested the performance and outcomes of supplemental screening modalities (US, MRI, and tomosynthesis) in women with these breast tissues. The authors found that about $80 \%$ of examinations were classified as grade b or c, however, observed also a $13-19 \%$ reclassification rate in this group with a change from non-dense to dense breast tissue, or vice versa, resulting in confusion and uncertainty among women. It was demonstrated that supplemental screening examinations find additional breast cancer with reduced recall rates, but false-positive rates were increased.

78. Berg WA, Bandos AI, Mendelson EB, Lehrer D, Jong RA, Pisano ED. Ultrasound as the primary screening test for breast cancer: analysis from ACRIN 6666. J Natl Cancer Inst. 2016;108(4). doi: https://doi.org/10.1093/jnci/djv367.

79. Giuliano V, Giuliano C. Improved breast cancer detection in asymptomatic women using 3D-automated breast ultrasound in mammographically dense breasts. Clin Imaging. 2013;37(3):4806. https://doi.org/10.1016/j.clinimag.2012.09.018.

80. Saslow D, Boetes C, Burke W, Harms S, Leach MO, Lehman CD, et al. American Cancer Society guidelines for breast screening with MRI as an adjunct to mammography. CA Cancer J Clin. 2007;57(2):75-89.

81. Sardanelli F. Considerations on the application of EUSOMA criteria for preoperative MRI. Breast. 2013;22(3):368-9. https:// doi.org/10.1016/j.breast.2013.02.016.
82. Mann RM, Balleyguier C, Baltzer PA, Bick U, Colin C, Cornford E, et al. Breast MRI: EUSOBI recommendations for women's information. Eur Radiol. 2015;25:3669-78. https://doi.org/10.1007/ s00330-015-3807-z.

83. Riedl CC, Luft N, Bernhart C, Weber M, Bernathova M, Tea MK, et al. Triple-modality screening trial for familial breast cancer underlines the importance of magnetic resonance imaging and questions the role of mammography and ultrasound regardless of patient mutation status, age, and breast density. J Clin Oncol. 2015;33(10): 1128-35. https://doi.org/10.1200/JCO.2014.56.8626.

84. Schrading S, Kuhl CK. Mammographic, US, and MR imaging phenotypes of familial breast cancer. Radiology. 2008;246(1):5870. https://doi.org/10.1148/radiol.2461062173.

85. Phi XA, Saadatmand S, De Bock GH, Warner E, Sardanelli F, Leach MO, et al. Contribution of mammography to MRI screening in BRCA mutation carriers by BRCA status and age: individual patient data meta-analysis. Br J Cancer. 2016;114(6):631-7. https://doi.org/10.1038/bjc.2016.32.

86. Emaus MJ, Bakker MF, Peeters PH, Loo CE, Mann RM, de Jong $\mathrm{MD}$, et al. MR imaging as an additional screening modality for the detection of breast cancer in women aged 50-75 years with extremely dense breasts: the DENSE Trial Study Design. Radiology. 2015;277(2):527-37. https://doi.org/10.1148/radiol.2015141827.

87. Checka CM, Chun JE, Schnabel FR, Lee J, Toth H. The relationship of mammographic density and age: implications for breast cancer screening. AJR Am J Roentgenol. 2012;198(3):W292-5. https://doi.org/10.2214/AJR.10.6049.

88. Vachon CM, Pankratz VS, Scott CG, Maloney SD, Ghosh K, Brandt KR, et al. Longitudinal trends in mammographic percent density and breast cancer risk. Cancer Epidemiol Biomark Prev. 2007;16(5):921-8. https://doi.org/10.1158/1055-9965.EPI-061047.

89. Freer PE. Mammographic breast density: impact on breast cancer risk and implications for screening. Radiographics. 2015;35(2): 302-15. https://doi.org/10.1148/rg.352140106.

90. King V, Brooks JD, Bernstein JL, Reiner AS, Pike MC, Morris EA. Background parenchymal enhancement at breast MR imaging and breast cancer risk. Radiology. 2011;260(1):50-60. https://doi.org/ 10.1148/radiol.11102156.

91. Dontchos BN, Rahbar H, Partridge SC, Korde LA, Lam DL, Scheel JR, et al. Are qualitative assessments of background parenchymal enhancement, amount of fibroglandular tissue on MR images, and mammographic density associated with breast cancer risk? Radiology. 2015;276(2):371-80. https://doi.org/10.1148/radiol. 2015142304. 